\title{
Nikos Donos: Peri-implantitis: is it a problem?
}

Please send any ideas for feature articles for consideration to:

Ruth Doherty,

Managing Editor,

British Dental Journal,

The Macmillan Building,

4-6 Crinan Street,

London,

N1 9XW

Email: r.doherty@nature.com

Nikos Donos shares his views on the problem of peri-implantitis, the teeth versus implants debate and the usefulness of CPD.

\section{Why did you choose a career in implantology?}

Implant dentistry is an integral part of periodontology since it allows us to provide restorative solutions for patients who have suffered tooth loss due to periodontal disease. Therefore, from a therapeutic perspective, implant dentistry opens up a new opportunity for us to be able to provide different restorative and therapeutic solutions for these patients.

From a research point of view, the reason that I became involved with implant dentistry is because I find the biological processes of osseointegration, wound healing and the regeneration of the lost bone around the area that requires implants fascinating.

\section{What could be done to minimise the incidence of peri-implantitis?}

Peri-implantitis could be considered as one of the emerging problems in implant dentistry. In order to be able to appreciate the extent of the problem, we need to know the prevalence of peri-implantitis. Unfortunately, we are still not very clear on this. It seems that the reported numbers are variable and not always comparable, with a recent systematic review (from the 2012 EAO consensus ${ }^{1}$ ) indicating that the "prevalence of periimplantitis seems to be in order of $10 \%$ of implants and 20\% of patients during 5-10 years after implant placement'. To reduce the clinical problem, firstly I think

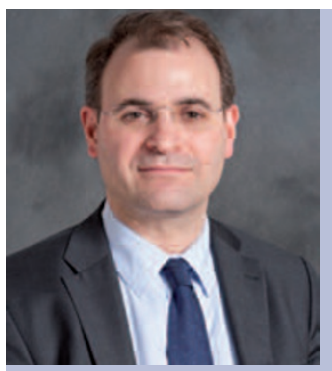

Professor Nikos Donos is the Head and Chair of Periodontology and the Director of Research at the UCL-Eastman Dental Institute in London. Nikos leads the Clinical Investigation Centre at the Eastman which specialises in the provision of randomised control trials (RCTs) and clinically applicable translational research studies. He qualified in dentistry at the Aristotle University of Thessaloniki, Greece in 1992 and completed his training as a specialist in periodontology at the Royal Dental College, University of Aarhus, Denmark. In 2001 Professor Donos joined the Eastman Dental Institute where he was appointed as Professor in Periodontology in 2005. His research has three main themes: wound healing, infection \& inflammation and evidence-based oral health. Professor Donos' work on wound healing encompasses translational research in soft and hard tissue regeneration, healing processes following non-surgical and surgical procedures in health and in chronic diseases and implant dentistry. The inflammation \& infection theme covers the area of periodontal medicine and its association with chronic general health diseases. In 2011, Professor Donos received the IADR/Straumann award for Regenerative Periodontal Medicine. Professor Donos is an Honorary Professor at the Universtiy of Hong Kong and Adjunct Professor at Griffiths Univerisity in Australia.

that there should be appropriate selection of patients. Implants are not always the appropriate treatment for everybody and it might be that we should use conventional dental procedures to restore some patients. Specifically in periodontitis patients we need to be careful about the timing of the placement in order to ensure that the periodontal disease is completely treated and the periodontal condition is stabilised before the initiation of implant surgery. Secondly, I think that it is imperative that the dentists who are involved in implant dentistry should be properly trained for the surgical and/ or restorative aspects of implants.

At the same time, a proper and early diagnosis of peri-implantitis is necessary and this can be achieved using an appropriate individual-based recall and maintenance system after treating your patients, where clinical and radiographical evaluation is performed in regular intervals. We should ensure that patients treated have very low plaque scores and no bleeding on probing. Thus, all the known risk factors, including systemic aspects, that could be associated with periimplantitis should be kept under control.

Though the dentist who places/restores the implants has particular responsibility, the dental hygienists should also have further CPD training in this area.

Do you feel that implants could replace the need for endodontics?

Without being a specialist in the area, I would think that when a tooth can 
be maintained with endodontic treatment, then it should be the first choice of treatment. However, performing endodontics just for the benefit of the procedure when the tooth cannot be restoratively maintained in the longterm is not advisable. In this case the treatment option of implants would perhaps be more favourable if bone is available in the area and the overall periodontal and dental condition allows it. Therefore, in such a decision-making process, all restorative aspects of the site and the oral cavity should be taken into account.

\section{When running a randomised con- trolled clinical trial (RCT), what are the main pitfalls to be avoided?}

In implant dentistry, there are problems in interpreting previous literature due to lack of definition or lack of clarity on what constitutes the survival or success of implants, and regarding the different risk factors affecting implant survival. Recently, our team published a systematic review on the quality of the studies of implant survival in the long term where this issue was discussed in detail. $^{2}$

Some examples of areas that need to be carefully considered when designing new clinical studies are:

1. A proper definition of implant survival

2. Appropriate sample size calculations

3. Appropriate statistical methodology for evaluating the relevant outcome

4. Defining the population of the study i.e. periodontitis patient outcomes.

\section{What do you feel are the main problems in oral health that further research could find an answer for?}

As a periodontist obviously I am biased towards a periodontology-related answer. One existing area could be the susceptibility to periodontal disease. In order to obtain further knowledge in this area, new platform technologies and methodologies, on the bacterial and genetic elements affecting periodontal disease, could be utilised.

In addition, diagnostic tests which could allow easy sampling, such as of saliva to identify biomarkers, might be a potential area of research which could help to predict the patients who may be prone to developing periodontal disease (again, significant research is performed in the area).

In terms of treatment, I think any new method or principle that would lead to regeneration of lost periodontal tissues would make a massive impact. Though today, we have treatment solutions that lead to periodontal regeneration, I think there is still a lot of research to be done in that area. Stem cells might be a way forward, even though today we still do not have a treatment that could be readily applied in a clinical setting.

In implant dentistry, we have progressed significantly in terms of surgical techniques and developing surfaces that accelerate osseointegration, but now we are facing the clinical problem that when complications arise we do not have a predictable treatment to resolve the problem and further research in this area is needed.

\section{What are you most proud of in your career to date?}

I am very proud of my department and my team at the Eastman. I have the privilege to work with great colleagues, who all work very hard in their own areas. I am proud that my team not only has a significant output based on high impact research but also provides a high level of clinical training for our graduates and excellent service for our patients.

In terms of personal achievement, one of the highlights I am particularly proud of is the IADR Periodontal Regenerative Medicine award that I received in San Diego in 2011 which essentially epitomises a significant part of my career efforts in the field of wound healing and tissue regeneration.

\section{How important is the role of nutrition in periodontology and implant maintenance?}

I think that nutrition is still an area of exploration within periodontology and certainly, in terms of implant dentistry it is still at an early stage. In generic terms, if somebody is not following a healthy diet, we know that this might have an effect on the periodontal condition and hence possibly on implant tissue-related problems. We know that there is emerging evidence that obesity, which is one of the greatest health problems in the UK, might also have an association with periodontal diseases. Overall, it is an area that requires further research.

\section{Would you encourage more GDPs to become involved in practice-based research?}

It would be an exciting development if more GDPs became regularly involved in research. They represent an enormous resource for recruitment of research patients, which is not necessarily well utilised in the UK at the moment. We, at the Eastman, have set up a network of GDPs in North London who recruit patients for an ongoing diabetic study. It has been a very rewarding process, because the GDPs wanted to be involved and I think they can see the benefit of recruiting patients for research from their practices. It is important to emphasise that the government also provides different funding opportunities for practicebased research through the NIHR.

I think that the clincial academics need to take the responsibility to engage and motivate undergraduate students about research while they are in dental school and make them aware that research is not necessarily only part of a purely academic career; that they can contribute through their everyday practice as GDPs.

\section{What is your view on the effective-} ness of the current CPD system?

CPD is very important. I think the UK was one of the first countries in Europe that actually moved towards a formal CPD system. It demonstrates that there is a continuous need for knowledge and stimulates dentists to be up to date with their profession. It also has very positive effect in terms of safety for the public. For example, I think that it has had an enormous positive impact on communication to the dental team around the topic of peri-implantitis.

\section{What advice would you give to a} young dentist leaving university?

If one decides to be a GDP, he/she should ensure that they keep updated via CPD. Make an effort to involve yourself with research because it will 
make your day-to-day practice more exciting. At any point in your practice, if you feel that you need further training do not hesitate to proceed with post-graduate education in one of the specialties in dentistry.

\section{If you weren't working in the field of dentistry, what would you do?}

The field of dentistry is rewarding because you may help patients through treatment but it is also stimulating by allowing you to further promote your interests through research. Therefore, I would do a profession that would allow me to interact with people and also to do research. History is one of my hobbies. Historians are very analytical individuals and history provides a lot of information on how things have developed.

\section{Top 5 tips for patients to encourage them to take care of their gums?}

1. Visit your dentist and request periodontal charts, and if necessary
X-rays (if there are clinical problems)

2. Invest time in having someone demonstrate how to brush your teeth properly either with a manual or electric tooth brush

3. Invest not only in a good manual or electric toothbrush but also in interdental cleaning using dental floss or interdental brushes

4. Ensure that from a young age you visit the dentist at regular intervals (according to your needs as set by the dentist) and attend a hygienist who, together with the dentist, is able to follow up your oral care

5. Quit smoking, if you are a smoker, and keep in good general health.

Interview by Ruth Doherty, $B D J$ Managing Editor.

1. Mombelli A, Muller N, Cionca N. The epidemiology of peri-implantitis. Clin Oral Impl Res 2012; 23 (Suppl 6): 67-76.

2. Needleman, I, Chin, S, O'Brien T, Petrie A, Donos N. Systematic review of outcome measurements and reference group(s) to evaluate and compare implant success and failure. J Clin Periodonto/ 2012; 39: 122-132.

\section{Further reading}

Donos N, Laurel L, Mardas N. Hierarchical decisions on teeth versus implants in the periodontitis susceptible patient: the modern dilemma. Periodontology 2000 2012; 59: 89-110.

Donos N. Summary of: Specialists' management decisions and attitudes towards mucositis and peri-implantitis. Br Dent J 2012; 212: 30-31.

Dereka X, Mardas N, Chin S, Petrie A, Donos N. A systematic review on the association between genetic predisposition and dental implant biological complications. Clin Oral Implants Res 2012; 23: 775-788.

Nibali L, Donos N. Radiographic bone fill of peri-implantitis defects following nonsurgical therapy: report of three cases. Quintessence Int 2011; 42: 393-397.

Donos N, Mardas N, Buser D. An outline of competencies and the appropriate postgraduate educational pathways in implant dentistry. Eur J Dent Educ 2009; 13 (Suppl 1): 45-54.

Claffey N, Clarke E, Polyzois I, Renvert S. Surgical treatment of peri-implantitis. J Clin Periodonta/2008; 35: 316-332.

Lindhe J, Meyle J. Peri-implant diseases: Consensus report of the sixth European Workshop on Periodontology. J Clin Periodontal 2008; 35 (Suppl 8): 282-285.

Lang N P, Berglundh T. Periimplant disease: where are we now? Consensus of the seventh European Worshop in

Periodontology. J Clin Periodontol 2011; 11 (Suppl): 178-181.

Professor Donos will be speaking at this month's Association of Dental Implantology expert panel consensus meeting on Monitoring, Diagnosis and Treatment of Peri-Implant Disease on 19 November 2012 at Savoy Place, Westminster, London. More information can be found at http://www.adi.org. uk/profession/events/consensus12/index.htm 